Received: 9 March 2019, Revised: 18 March 2019

Accepted: 8 April 2019, Published: 28 April 2019

Available online at: http://e-journal.unair.ac.id/index.php/IMHSJ

\title{
KOMPLIKASI KEHAMILAN DAN PERSALINAN PADA KEHAMILAN REMAJA
}

\section{COMPLICATION OF PREGNANCY AND CHILDBIRTH IN ADOLESCENCE PREGNANCY}

\author{
Faqihati Husna ${ }^{1}$, Muhammd Ilham Aldika Akbar ${ }^{2}$, Rize Budi Amalia ${ }^{2}$ \\ 1. Program Studi Pendidikan Bidan, Fakultas Kedokteran, Universitas \\ Airlangga \\ 2. Fakultas Kedokteran, Universitas Airlangga \\ Alamat korespondensi: \\ Jalan Kacapiring II no.14 Pare, Kediri 64212
}

\begin{abstract}
Abstrak
Latar Belakang: Menurut UNICEF, setiap lima kelahiran bayi terdapat satu bayi lahir dari ibu dengan usia dibawah 19 tahun. Kehamilan pada remaja usia 15-19 tahun di negara berkembang mencapai angka 21 juta. Kehamilan remaja merupkan masalah yang tersebar di seluruh dunia dan berdampak terhadap kesehatan ibu dan anak. (Mukhopadhyay, 2010), secara luas kematian yang disebabkan oleh kehamilan merupakan penyebab utama kematian anak perempuan usia 15-19 tahun (WHO, 2017). Remaja memiliki risiko komplikasi kehamilan yang tinggi, salah satunya adalah persalinan prematur, IUGR dan pre-eklamsia. (Baker, 2007).Terjadi peningkatan risiko komplikasi sebesar 2 kali lipat pada kehamilan remaja dibandingkan kehamilan pada wanita usia 20-an (Utomo I. D., 2013), Penelitian ini bertujuan untuk mencari hubungan kehamilan remaja dengan komplikasi kehamilan dan persalinan. Metode: Penelitian ini menggunakan metode analitik observasional dengan pendekatan retrospektif cross sectional dengan jumlah sampel 40 dan diambil dengan teknik cosecutive sampling. Hasil: Komplikasi pada kehamilan remaja mencapai $60 \%$. Hasil analisis hubungan kehamilan remaja dengan komplikasi kehamilan $(p$ value $=0,0100 \mathrm{OR}=6)$, anemia $(p$ value $0,013 \mathrm{OR}=7,364)$, defisiensi gizi $p$ value $=0,400)$, prekalmisa/eklamsia ( $p$ value $=0,300)$, komplikasi persalinan $(p$ value $=1,000)$, persalinan SC $(p$ value $=1,000)$ dan $\operatorname{KPD}(p$ value $=1,000)$. Kesimpulan: Pada penelitian ini kehamilan remaja berpengaruh pada komplikasi kehamilan dengan penyulit dominan anemia dan tidak berpengaruh pada komplikasi persalinan.
\end{abstract}

Kata kunci : kehamilan remaja, komplikasi kehamilan, komplikasi persalinan

\begin{abstract}
Backgrounds: According to UNICEF, every five babies born there is one baby born to a mother under the age of 19 years. Pregnancy in adolescents aged 15-19 years in developing countries reaches 21 million. Teenage pregnancy was a problem that spread throughout the world and had an impact on maternal and child health. (Mukhopadhyay, 2010), widely deaths caused by pregnancy are the main cause of death for girls aged 15-19 years (WHO, 2017). Adolescents had a high risk of pregnancy complications, one of which is premature labor, IUGR and pre-eclampsia. (Baker, 2007). There has been a 2-fold increase in the risk of complications in adolescent pregnancies versus pregnancies in women in their 20s (Utomo I. D., 2013). Methods: This study were observational analytic method with a retrospective cross sectional approach with 40 samples and was taken by cosecutive sampling technique. Results: Complications in adolescent pregnancy reach $60 \%$. The results of the analysis of the relationship of adolescent pregnancies with complications of pregnancy showed ( $p$ value $=0,0100 \mathrm{OR}=6$ ), anemia ( $\mathrm{p}$ value $0,013 \mathrm{OR}=7,364)$, nutritional deficiency $(\mathrm{p}$ value $=0,400$ ), preeclampsia/eclampsia ( $p$ value $=0,300$ ), labor complications ( $p$ value $=1,000$ ), sectio caesaria $(\mathrm{p}$ value $=1,000)$ dan premature rupture of membrane $(\mathrm{p}$ value $=1,000)$
\end{abstract}

Keywords: teenage pregnancy, pregnancy complications, labor complications 


\section{PENDAHULUAN}

Masa remaja adalah masa transisi dengan perubahan dan perkembangan fisik, psikologi dan cara berpikir secara cepat. Pada masa ini, seringkali remaja ingin mencoba hal baru dan berani mengambil keputusan sendiri tanpa adanya pertimbangan terhadap risiko jangka pendek maupun panjangnya (Kementerian Kesehatan RI, 2015). Pernikahan usia muda di Indonesia dipengaruhi oleh berbagai faktor yang sebagian besar berhubungan dengan budaya dan permasalahan ekonomi. Namun dampak dari pernikahan usia dini dapat mengarah pada beberapa aspek yang akan merugikan pihak perempuan dan anak (Fadlyana, 2009). Menurut UNICEF, setiap lima kelahiran bayi terdapat satu bayi lahir dari ibu dengan usia dibawah 19 tahun. Kehamilan pada remaja usia 15-19 tahun di negara berkembang mencapai angka 21 juta. Kehamilan remaja merupkan masalah yang tersebar di seluruh dunia dan berdampak terhadap kesehatan ibu dan anak. (Mukhopadhyay, 2010). Komplikasi kehamilan dan persalinan merupakan penyebab utama kematian perempuan usia 15-19 tahun (WHO, 2018). Dalam satu studi menyebutkan bahwa persalinan remaja di negara berkembang lebih tinggi dengan sectio ceasaria. Hal ini dapat berhubungan dengan ketidakmatangan tulang panggul yang dapat berisiko terjadi komplikasi kebidanan (WHO, 2004). Pubertas dipengaruhi oleh banyak faktor antara lain ras, keturunan, status gizi dan kondisi kesehatan secara umum (Ramadhy,2011). Maka dari itu dilakukan penelitian untuk mengetahui hubungan antara kehamilan remaja dengan komplikasi kehamilan dan persalinan di Puskesmas Medokan Ayu dan Puskesmas Tanahkali Kedinding.

\section{METODE}

Desain penelitian menggunakan analitik observasional dengan pendektan cross sectional dengan jumlah sampel 40 dan diambil dengan teknik cosecutive sampling yaitu semua subyek yang memenuhi kriteria dimasukkan dalam penelitian sampai jumlah subyek yang diperlukan terpenuhi.Analisis data menggunakan uji analisis chi-square 
Indonesian Midwifery and Health Sciences Journal

HASIL DAN PEMBAHASAN

Tabel 1 Hasil analisis chi square komplikasi kehamilan

\begin{tabular}{|c|c|c|c|c|c|}
\hline Variabel Independen & \multicolumn{2}{|c|}{ Komplikasi } & Total & Pvalue & $\begin{array}{c}\text { OR } \\
(95 \% \mathrm{CI})\end{array}$ \\
\hline & \multicolumn{2}{|c|}{ Komplikasi Kehamilan } & & & \\
\hline & $\mathrm{Ya}$ & Tidak & & & \\
\hline usia 10 -19 tahun & $12(60.0 \%)$ & $8(40.0 \%)$ & $20(100.0 \%)$ & \multirow{3}{*}{0,0100} & \\
\hline usia 20-35 tahun & $4(20.0 \%)$ & $16(80.0 \%)$ & $20(100.0 \%)$ & & $\begin{array}{c}6,000 \\
(1.458-24.686)\end{array}$ \\
\hline \multirow[t]{3}{*}{ Total } & $16(40.0 \%)$ & $24(60.0 \%$ & $40(100.0 \%)$ & & \\
\hline & \multicolumn{2}{|c|}{ Anemia } & & & \\
\hline & $\mathrm{Ya}$ & Tidak & & & \\
\hline usia $\leq 19$ tahun & $9(45 \%)$ & $11(55 \%)$ & $20(100 \%)$ & & \\
\hline usia 20-35 tahun & $3(15 \%)$ & $17(85 \%)$ & $20(100 \%)$ & 0,0130 & $\begin{array}{c}7,364 \\
(1,337-40,548)\end{array}$ \\
\hline \multirow[t]{3}{*}{ Total } & $12(30 \%)$ & $28(70 \%)$ & $40(100 \%)$ & & \\
\hline & \multicolumn{2}{|c|}{ Defisiensi gizi } & & & \\
\hline & $\mathrm{Ya}$ & Tidak & & & \\
\hline Usia $\leq 19$ tahun & $5(25 \%)$ & $15(75 \%)$ & $20(100 \%)$ & & \\
\hline usia 20-35 tahun & $2(10 \%)$ & $18(90 \%)$ & $20(100 \%)$ & 0,400 & - \\
\hline \multirow[t]{3}{*}{ Total } & $7(17,5 \%)$ & $33(82,5 \%)$ & $40(100 \%)$ & & \\
\hline & \multicolumn{2}{|c|}{ PE/Eklamsia } & & & \\
\hline & $\mathrm{Ya}$ & Tidak & & & \\
\hline usia $\leq 19$ tahun & $0(0 \%)$ & $20(100 \%)$ & $20(100 \%)$ & & \\
\hline usia 20-35 tahun & $1(5 \%)$ & $19(95 \%)$ & $20(100 \%)$ & 0,300 & - \\
\hline Total & $1(2,5 \%)$ & $39(97,5 \%)$ & $40(100 \%)$ & & \\
\hline
\end{tabular}

Hasil penelitian dari 20 orang ibu usia remaja ( $\leq 19$ tahun) didapatkan komplikasi kehamilan sebanyak 60\% (45\% anemia dan 25\% defisiensi gizi) dan pada 20 orang dari kelompok usia reproduksi sehat (20-35 tahun) mengalami komplikasi kehamilan sebesar 20\% (15\% anemia, 10\% defisiensi gizi dan 5\% preeklamsia). Penyulit ISK dan IUGR tidak ditemui pada responden dari dua kelompok usia. Hasil analisis data statistik antara kehamilan remaja dengan komplikasi kehamilan menunjukkan hasil yang signifikan yaitu $p$ sebesar $0,01(p$ $<0,05$ ), yang berarti ada hubungan antara kehamilan remaja dengan komplikasi kehamilan. Hasil ini sesuai dengan penelitian oleh Adeyinka (2010) bahwa remaja berisiko memiliki komplikasi lebih tinggi selama hamil dengan nilai $\mathrm{p}$ sebesar 
0,002. Pada penelitian ini nilai OR sebesar 6 bermakna kehamilan remaja memiliki risiko 6 kali lebih besar terjadi komplikasi kehamilan daripada kemahilan usia reproduksi sehat. Hasil tersebut sesuai dengan penelitian Destaria (2011) bahwa angka kesakitan dan angka kematian ibu dan bayi pada kehamilan remaja dua hingga empat kali lebih tinggi dibandingkan dengan kehamilan di usia 20-35 tahun. Usia dan fisik wanita memiliki pengaruh pada proses kehamilan, kesejahteraan janin dan proses persalinan. WHO merekomendasikan usia yang dianggap aman untuk menjalani kehamilan dan persalinan adalah usia 20-35 tahun. Kehamilan kurang dari 20 tahun belum optimal secara fisik, emosi cenderung belum stabil dan mental mudah mengalami guncangan (Manuaba, 2010).

Komplikasi kehamillan dalam penelitian ini ditetapkan apabila terdapat satu atau lebih penyulit kehamilan antara lain anemia, defisiensi gizi, preeklamsia/eklamsia, ISK dan IUGR. Hasil dari analisis data statistika pada masing - masing penyulit menunjukkan anemia memiliki nilai $\mathrm{p}$ sebesar 0,013 yang bermakna ada hubungan antara kehamilan remaja dengan anemia. Hasil penelitian ini sejalan dengan penelitian Socolov (2017) dan Yasmin et al (2014) yang menyatakan ada hubungan kehamilan usia muda dengan kejadian anemia. Penelitian oleh Destaria (2011) dan Pigai (2018) menyatakan secara statistik tidak ditemukan hubungan yang bermakna antara anemia dalam kehamilan dengan kehamilan di usia muda. Pada penelitian ini, nilai OR sebesar 7,3, maka kehamilan remaja memiliki 7,3 kali lebih besar terjadi anemia daripada kehamilan pada usia reproduksi sehat. Secara umum prevalensi anemia menurut data Kemenkes RI (2013) menunjukkan bahwa pada wanita lebih tinggi (23.9\%) dibanding dengan laki-laki $(18,4 \%)$. Penelitian lain menyebutkan bahwa pada remaja putri prevalensi anemia mencapai (27,5\%) (Priyanto, 2018). Anemia pada kehamilan sebagian besar disebabkan oleh kekurangan gizi, terutama zat besi dan asam folat. Beberapa studi menyatakan bahwa ibu hamil remaja memiliki prevalensi lebih tinggi terjadi anemia daripada ibu hamil dengan usia lebih tua (WHO, 2004). Kehamilan di remaja merupakan salah satu faktor terjadinya anemia dalam kehamilan. Anemia pada saat kehamilan remaja kemungkinan disebabkan oleh kurangnya pengetahuan terhadap gizi saat hamil dan dapat berpengaruh pada rendahnya kesadaran mengonsumsi tambahan zat besi. Anemia pada kehamilan 
dapat menjadikan penyulit lain saat kehamilan ,persalinan, nifas dan bayi lahir dengan anemia (Manuaba, 2004)

Hasil analisis statistik pada penyulit defisiensi gizi didapatkan hasil yang tidak signifikan dan tidak ada hubungan antara kehamilan remaja dengan defisiensi gizi. Defisiensi gizi pada penelitian ini menggunakan indeks masa tubuh sebelum hamil sebagai klasifikasi status gizi, IMT dibawah 18,5 dikategorikan sebagai KEK. Kekurangan energi kronik sebelum hamil dapat berpengaruh pada berat badan lahir bayi dan anemia. Hasil penelitian yang tidak berhubunan sesuai dengan hasil analisis oleh Gibbs (2015) bahwa tidak ditemukan perbedaan yang signifikan pada berat badan sebelum hamil antara remaja dan orang dewasa. Penelitian oleh Santos (2002) menyatakan bahwa perbedaan berat badan lahir bayi sesuai dengan status gizi sebelum hamil (IMT pra-hamil) dan total kenaikan berat badan selama hamil. Menurut Daley (2013) kehamilan remaja memiliki risiko terjadi defisiensi gizi karena remaja cenderung tidak perhatian pada kebutuhan nutrisi. Remaja memiliki kebutuhan gizi yang berbeda untuk proses pertumbuhan dan kebutuhan gizi saat hamil menjadikan status gizi perlu menjadi perhatian tenaga kesehatan. Ibu yang mengalami defisiensi gizi sebelum hamil atau selama kehamilan cenderung melahirkan bayi yang menderita kerusakan otak dan sumsum tulang karena sistem saraf pusat sangat peka pada 2-5 minggu pertama. Defisiensi gizi juga berdampak pada bayi, kemungkinan bayi lahir dengan berat badan rendah $(<2500$ gram) (Arisman, 2009).

Penyulit kehamilan yang diteliti selanjutnya adalah preeklamsia/eklamsia, didapatkan hasil yang tidak signifikan dan tidak ada hubungan kehamilan remaja dengan preeklamsia/eklamsia. Hasil tersebut sejalan dengan penelitian oleh Gabriela (2017), Traisrisilp K (2015) bahwa kejadian preeklamsia/eklamsia pada semua usia sama, namun tidak sejalan dengan penelitian oleh Tebeu (2011) dan Adeyinka (2009) yang menyatakan bahwa kehamilan remaja menunjukkan hasil yang signifikan terhadap kejadian preeklamsia/eklamsia $(p=0,001)$. Peningkatan resistensi insulin pada masa pubertas dan terjadinya sindrom metabolic selama kehamilan, dapat menajdi faktor peningkatan tekanan darah dan preeklamsia pada ibu usia kurang dari 20 tahun (Gold,2014). Pada penelitian oleh Pingel (2017) menyatakan bahwan preeklamsia tidak tergantung pada usia ibu. Penyulit ISK dan 
IUGR tidak ditemukan pada kedua kelompok usia namun pada penelitian Alouni (2010) Pingel (2017) Socolov (2017) menyatakan bahwa insiden terjadi infeksi saluran kemih lebih tinggi pada remaja. Penelitian oleh Kongnyuy (2008), IUGR tidak secara signifikan terjadi lebih tinggi pada remaja. Pada penelitian ini hasil penelitian kurang signifikan karena tidak ditemukan kejadian pada dua penyulit.

Tabel 2. Hasil analisis chi square komplikasi persalinan

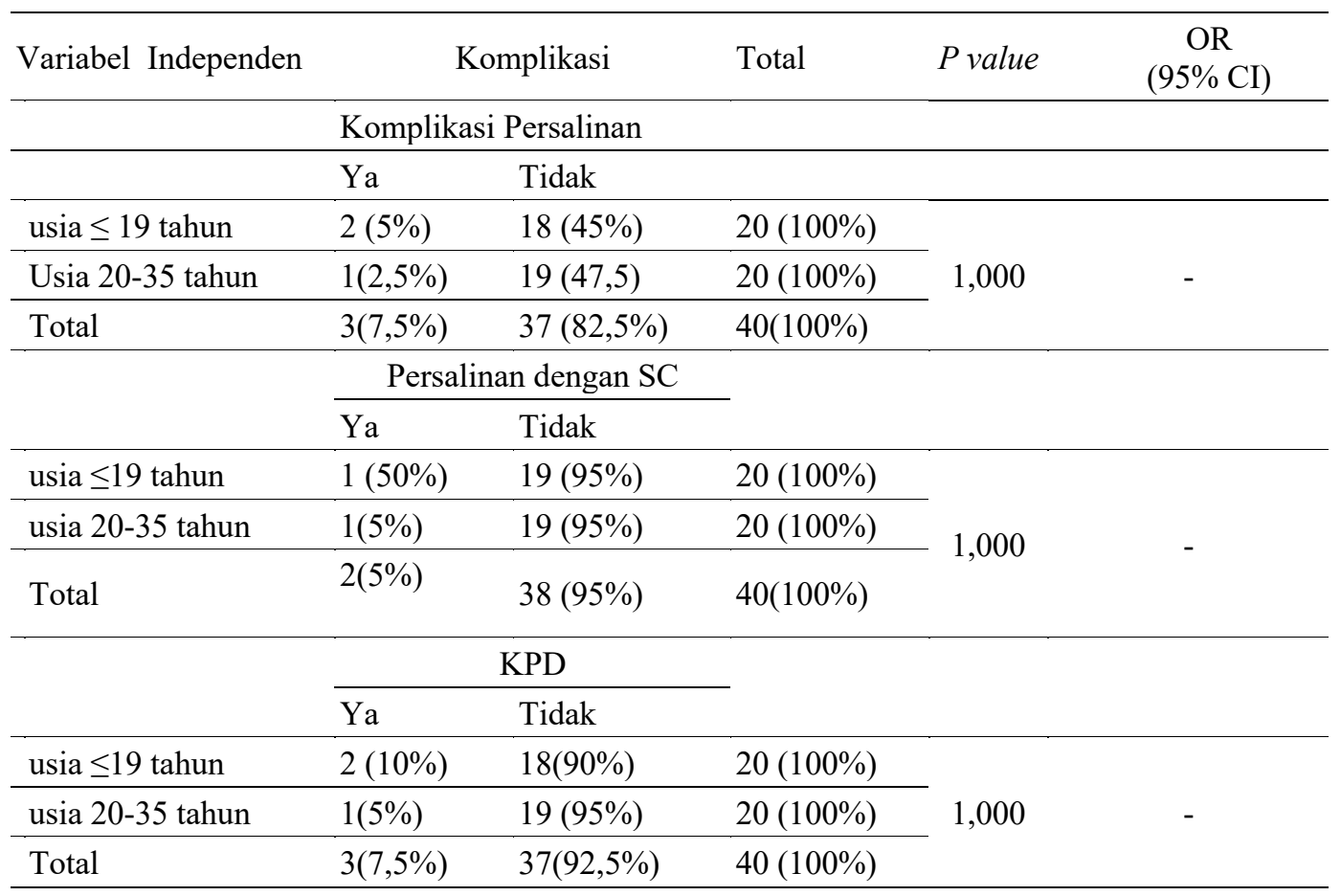

Hasil penelitian dari 20 orang ibu usia remaja (10-19 tahun) didapatkan komplikasi persalinan sebanyak 5\% (5\% persalinan SC dan $10 \% \mathrm{KPD})$ dan pada 20 orang kelompok usia reproduksi (20-35 tahun) mengalami komplikasi kehamilan sebesar 2,5\% (5\% persalinan SC dan 5\% KPD). Penyulit persalinan dengan vakum, persalinan prematur dan persalinan lama tidak ditemui pada responden dari dua kelompok usia. Komplikasi persalinan pada penelitian ini ditetapkan apabila terdapat satu atau lebih penyulit persalinan. Hasil dari analisis statistika pada masing masing penyulit antara lain persalinan dengan vakum ( tidak ditemukan kasus), persalinan dengan $\mathrm{SC}(\mathrm{p}=1), \mathrm{KPD}(\mathrm{p}=1)$, persalinan prematur (tidak ditemukan kasus) dan persalinan lama(tidak ditemukan kasus). Data penyulit persalinan tersebut kemudian dianalisis untuk mencari hubungan kehamilan remaja dengan komplikasi persalinan. Hasil data statistik menunjukkan 
hasil yang tidak signifikan, yang berarti tidak ada hubungan antara kehamilan remaja dengan komplikasi persalinan.

Hasil penelitian ini sejalan dengan penelitian Socolov (2017) bahwa remaja lebih rendah terjadi persalinan SC dan instrumental daripada orang dewasa. Pingel (2017) menyatakan persalinan lama dan operasi caesar pada remaja tidak berbeda dengan kelompok reproduksi sehat. Hasil penelitian ini juga sejalan dengan Septiani (2017) yang menjelaskan bahwaperbandingan kejadian persalinan dengan tindakan pada ibu remaja dan ibu usia reproduksi sehat tidak signifikan. Penelitian lain menyebutkan ibu remaja memiliki risiko lebih rendah mengalamai persalinan tindakan khususnya persalinan operatif karena rata-rata berat badan lahir bayi pada ibu remaja rendah (Kammini, 2014). Penyebab rendahnya kejadian persalinan dengan tindakan padaibu remaja karena fungsi myometrium, elastisitas jaringan ikat yang baik dan BBLR (Demirci, 2016). Penelitian Azevedo (2015) menyatakan risiko KPD sebesar 5,81 kali lebih besar pada remaja. Selaput ketuban yang tidak siap menerima rangsangan dari luar karena sel sel mukosa serviks belum matang menjadi dapat penyebab ketuban pecah dini pada ibu usia remaja (Tadzqiroh,2018). Kongnyuy (2008) menjelaskan bahwa dengan adanya penyulit yang berbeda pada remaja maka upaya untuk mencegah dapat melalui kepatuhan kunjugan hamil. Program ANC terpadu yang berjalan di kota Surabaya Pada penelitian ini sedikitnya komplikasi persalinan dapat terjadi karena program Pemerintah Surabaya bahwa setiap ibu hamil remaja yang melakukan pemeriksaan kehamilan di puskesmas dilakukan rujukan ke rumah sakit karena dianggap kehamilan risiko tinggi, program tersebut sudah berjalan sejak tahun 2016. Sistim rujukan pada ibu hamil tersebut mendeteksi lebih awal kemungkinan komplikasi saat masa kehamilan, dengan penatalaksaan yang tepat dapat menekan terjadinya komplikasi persalinan

\section{SIMPULAN DAN SARAN}

Terdapat hubungan kehamilan remaja dengan komplikasi kehamilan dan tidak terdapat hubungan kehamilan remaja dengan komplikasi persalinan. Penelitian selanjutnya lebih baik dilakukan di rumah sakit yang menerima rujukan. 


\section{DAFTAR PUSTAKA}

Althabe F,et al.(2015). Adverse Maternal and Perinatal Otcomes in Adolescent Pregnancies : The Global Network's Maternal Newborn Health Registry Study. Reproduction Health Vol 12 Issue 2

Alouni S, et al.(2015).Risk Factors Of Teenage Pregnancies, Deliveries And Postpartum In The Department Of Loiret. Journal Gynecology Obtetric Biological Reproductive Volume 44 Isuue 5 443-500

Azevedo EF, et al. Einstein (Sao Paulo). 2015. Complication In Adolesscent Pregnancy:Systematic Review Of The Literatur.doi:10.1590/s167945082025RW3127.Epub 2015

Badan Pusat Stastistik. (2018). Presentase Perempuan Jawa Timur Usia 10 tahun ke Atasyang Kawin di Bawah Umur (Kurang dari 17 tahun) menurut Kabupaten/Kota, 2009-2016. Jakarta: Badan Pusat Statistika. Diperoleh dari https://jatim.bps.go.id/statictable/2017/06/09/465/persentaseperempuan-jawa-timur-usia-10-tahun-ke-atas-yang-kawin-di-bawah-umurkurang-dari-17-tahun-menurut-kabupaten-kota-2009-2016-.html [ diakses pada tanggal 12 November 2018]

Baker, Philip. Guhtrie,Kate Hutchinson, Cinsy. Kane Roslyn. Wellings, Kaye (2007). Teeenage Pregnancy and Reproductive Health. London: Royal Collage of Obstetricians and Gynaecologists. Diperoleh dari https://www.researchgate.net/publication/257654633 Teenage pregnancy and reproductive health [diakses pada tanggal 15 November 2018]

Batubara, , Jose RL (2010). Adolescent Development. Sari Pediatri vol 12 no 1. https://www.saripediatri.org/index.php/saripediatri/article/viewFile/540/47 6 [diakses pada tanggal 12 November 2018]

Daley AM (2013).Tailoring Clinical Services To Address The Unique Needs Of Adolescents From The Pregnancy Test To Parenthood.Current Problems in Pediatric and Adolescent Health Care

Daniel A. Adeyinka, Olanrewaju Olasimeji,Taye I.Adekanbi,Folasade E. Adeyinka, Yemisi Falope\&Chris Aimahku .(2010). Outcome of adolescent pregnancies in southwesternnigeria; acase conreol satudy, The Journal of Maternal-fetal\&Neonatal Medicine, 23;8, 785-789, DOI: $10.3109 / 1476705903572166$

D. Jeha, I. U. (2015). A review of the risks and consequences of adolescent pregnancy. Journal of Neonatal-Perinatal Medicine 8 (2015) , 1-8.

Demirci O,et al. (2016).effect of young maternal age on obstetric and perinatal outcome; result from the tertiary center in turkey. Balkan Medical Journal Vol 33 Issue 3 Page 344-349

Destaria. (2011). Perbandingan Luaran Maternal dan Perinatal Kehamilan Trimester 3 antara Usia Muda dan Usia Reproduksi Sehat. Skripsi. Universitas Diponegoro.

Fadlyana, Eddy. Shinta Larasaty (2009). Pernkahan Usia Dini dan Permasalahannya. Bandung: Sari Pediatri, Vol 11 no 2. Diperoleh dari https://saripediatri.org/index.php/sari-pediatri/article/view/607 [diakses pada tanggal 9 Desember 2018]

Gazala Yasmin, A. K. (2014). Teenage Pregnancy - Its Impact on Maternal and Fetal Outcome. International Journal of Scientifi c Study Vol $1 \mid$ Issue 6, 913. 
Gibbs CM, et al.(2013). The impact of early age at first childbirth on maternal and infant healt. Current Problems in Pediatric and Adolescent Health Care Vol 43 Issue 4,71-95

Hugo M R,et al.(2017). Family Context and individual Situation of teens before, during and after pregnancy in mexico city. BMC Pregnancy Childbirth Vol 17

Kamini S.(2014).Teenage Pregnancy ; Maternal And Fetal Outcomes.Journal of Dental and Medical Sciences Vol 13 Issue 4 Page 41-44

Kementrian Kesehatan RI.(2014).Profil Kesehatan Indonesia Tahun 2013. Jakarta : KemenkesRI

Kementerian Kesehatan RI. (2015). Situasi Kesehatan Reproduksi Remaja. Jakarta: Pusat Data dan Informasi.

Kongnyuy E J, et al.(2008). Adverse Perinatal Outcomes of Adolescent Pregancies in Cameroon. Maternal Child Health Journal Volume 12 Issue 2 149-54

Leppälahti S, Gissler M, Mentula M, et al. (2012). Trends in teenage termination of pregnancy and its ridk factors : A Population-based study in finlasn 19872009. Human Reproduction. Diperoleh dari https://www.ncbi.nlm.nih.gov/pmc/articles/PMC3753503/pdf/bmjopen2013-003225.pdf diakses pada tanggal [15 Februari 2019]

Lorraine Radford, Debra Allnock and Patricia Hynes (2015). Preventing and Responding to Child Sexual Abuse and Exploitation: Evidence review. United Nations Children's Fund (UNICEF) . diperoleh dari https://www.unicef.org/protection/files/Evidence_Review_SEA_(Radford et_al).pdf [diakses pada tanggal 12 November 2018]

Mangastomo, H. S. (2009). Luaran Maternal dan Perinatal pada Wanita Usia Kurang dari 20 tahun di RSUP Dr. Kariadi Semarang 2009. Skripsi. Universitas Diponegoro.

Manuaba,IAC.,I Bagus, dan IB Gde.2004. Ilmu Kebidanan,Penyakit Kandungan dan KB untuk Pendidikan Bidan..Jakarta:EGC

Manuaba,IAC.,I Bagus, dan IB Gde.2010.Ilmu Kebidanan,Penyakit Kandungan dan KB untuk Pendidikan Bidan.Edisi kedua.Jakarta:EGC

Mukhopadhyay, Prianka . R.N. Chaudhuri2, and Bhaskar Paul (2010). Hospitalbased Perinatal Outcomes and Complications in Teenage Pregnancy in India. Bangladesh: International Centrefor Diarrhoeal Disease Research.

Pigai,Otopina. (2018). Faktor - Faktor yang Berhubungan dengan Kejadian anemia Pada Ibu Hamil di Wilayah Kerja Puskesmas Sidotopo Wetan .Skripsi.Universitas Airlangga

Pingel, PE.,et al. (2017). Pregnancy outcomes in Youger and Older adolescent mothers with severe preeclampsia. Adolescent Health Medical Ther. Vol 6 Issue 8 81-86

Prawirohardjo.(2002). Ilmu Kebidanan. Jakarta:FKUI

Septiani, Raden.(2017).Perbandingan Luaran Maternal dan Neonatal pada Persalinan Ibu Remaja dengan Ibu Usia Reproduksi Sehat di RSUD Dr.M.Soewandhie Surabaya.Skripsi.UNAIR

Sloane dan Bennedict. (2009). Petunjuk lengkap kehamilan. Alih Bahasa, Anton Adiwiyoto.Jakarta:Pustaka Mina

Socolov DG,Lorga M, carauleanu,Ilea C, Blidaru I, Boiculese L.2017.Pregnancy during Adolescence and Associated Risk: An 8_Year Haspital Baed Cohort 
Study (2007-2014) in Romania, the Country wint the highest rate of teenage pregnancy in Europe.BioMed Research International volume 2017. Diperoleh dari https;//doi.org/10.1155/2017/92505016

Tadzqiroh,Ulufu. (2018). Analisis Faktor Risiko Yang Berhubungan Dengan Kejadian KPD Pada Ibu Bersalin Di RS PKU Muhammadiyah Surabaya. Skripsi. UNAIR

UNICEF. (2016). Kemajuan yang Tertunda : Analisis Data Perkawinan Usia Anak di Indonesia. Jakarta: Badan Pusat Statistika. Diperoleh dari https://www.unicef.org/indonesia/id/Laporan_Perkawinan_Usia_Anak.pdf [diakses pada tanggal 12 November 2018]

Utomo, Iwu. Utomo, Ariane (2013). Adolescent Pregnancy in Indonesia: A Literature Review. United Nations Population Fund (UNFPA), 1-11.

Utomo, Iwu. Utomo Ariane (2013). Indicators and Correlates of Adolescent. Australian Demographic and Social Research Institute, The Australian National University.

WHO. (2004). Adolescent pregnancy. Switzerland: Publications of the World Health Organization can be obtained from Marketing and Dissemination, World Health Organization. Diperoleh dari https://apps.who.int/iris/bitstream/handle/10665/42903/9241591455 eng.p df? sequence $=1$ [diakses pada 12 November 2018]

WHO. (2017). Family Planning Evidence Brief - Reducing early and unintended. Switzerland: Department of Reproductive Health and Research WHO. Diperoleh dari https://apps.who.int/iris/bitstream/handle/10665/255862/WHO-RHR17.10eng.pdf;jsessionid $=43 \mathrm{C} 6 \mathrm{C} 815 \mathrm{CD} 37472 \mathrm{DD} 2 \mathrm{DCA} 08085 \mathrm{C} 20 \mathrm{~F} 2 \mathrm{~A}$ ?se quence $=1$ [diakses pada 02 Desember 2018] 